\title{
The Effect of Emotional Intelligence on Organization Performance Using the Big Five Personality Traits": An Applied Study on Higher Education Institutions
}

\author{
Marwa Amin Sultan ${ }^{1 *}$ Professor Ahmed Maher ${ }^{2}$ Dr. Passent Ibrahim Tantawi ${ }^{1}$ \\ 1. Arab Academy for Science, Technology and Maritime Transport, Alexandria, P.O. Box 1029, Abukir, \\ Alexandria, Egypt \\ 2. Faculty of Commerce, University of Alexandria, P.O. Box 21526, Elshatby, Alexandria, Egypt \\ * E-mail of the corresponding author: marwa.sultan@aast.edu
}

\begin{abstract}
Purpose: The purpose of this paper is to investigate to what extent emotional intelligence (EI) affects organization performance through the Big Five personality traits (BFPT) in higher education institutions.

Design/Methodology: Based on the Structural Equation Model, this study examines 270 faculty members within a higher education institution, to test an estimated model presenting the effect of top management EI on organization performance in the presence of the BFPT. The hypothesized model indicates that there is no significance for the presence of the one of the dimensions of EI domain as an independent variable. Thus, this dimension is deleted and another hypothesized model is re-estimated.

Results/Findings: The findings revealed that EI would strongly predict organization performance through the BFPT. Specifically, only three out of four dimensions of EI would predict organization performance through only three effective dimensions out of five of the BFPT.

Theoretical and practical implications: The findings enable a better theoretical understanding of how BFPT mediates the effects of EI on organization performance. Furthermore, the implications from this study allows human resources professionals to improve investigating personalities of potential management before hiring, as well as training and developing current management, as stable management personalities within any organization are vital to achieve high performance.
\end{abstract}

Keywords: Emotional intelligence, Big Five Personality traits, and organization performance.

DOI: $10.7176 / \mathrm{JAAS} / 76-06$

Publication date:October $31^{\text {st }} 2021$

\section{Introduction}

Emotions have a great part in the place of work; they affect manners of employees and thus affect perceptions, understanding, and managing of such manners. Higher education institutions have their specific strategies which allow them to compete on a solid ground, all employees especially higher management need to use their emotions efficiently to achieve success. Crawford (2009) indicated that managers have great effect on their assistants' behavior affecting organization performance. Also, Walter et al. (2011) concluded that those high in EI are most truthful at influencing their employees, as they are more capable at understanding their employees' needs.

Emotionally sound individuals have better interpersonal communication by understanding their own emotions and others' emotions (Anwar et al.; 2017). Daniel Goleman (1995) highlighted on the importance of emotional intelligence (EI) for organizational success. Anwar and Sulaiman (2013) indicated that Goleman stressed on developing EI model in addition to implementing it for organizational effectiveness.

\section{Research Importance}

The study is important for higher education institution to improve their performance as they must stay competitive. Investigating the relationship between EI and organization performance in the higher education institutions through the BFPT and the DTT can contribute in improving organization performance which will aid in developing and recruiting top management who have high EI skills to handle challenges and improve their institutions performance. 


\section{Aim and Objectives}

The aim of this study is the relationship between EI and organization performance through the BFPT in private higher education institutions. Previous researches have investigated the topics of EI and organization performance and BFPT using different variables then what is used in this study. That is why the relationship between EI and organization performance mediated by the BFPT has been investigated in this research.

Private higher education institutions have an important role in supporting the higher education industry in any country. They must follow the best managerial strategies set and executed by stable top management personalities. This study provides insights for top management on how to develop and improve their personal competences to improve their organization performance.

\section{Literature Review and Hypotheses}

\section{4-1 Emotional Intelligence (EI)}

EI as a concept was raised since 1990, its definition was changed by a number of researchers. Salovey and Mayer (1990) were among the first researchers who defined EI as the ability to deal with emotions, such as regulating, understanding, perceiving, expressing, and assimilating emotion, then was tackled by Goleman (1995). It was concluded by Mayer and Salovey (1997) as a set of abilities, when they were explained as a set of emotion-related abilities, to perceive, evaluate, and direct emotion; to access and create feelings; to understand emotion and emotional knowledge; and to control emotions.

Miao et al. (2017a, 2017b) defined EI as "a constellation of behavioral dispositions and self-perceptions concerning one's ability to recognize, process, and utilize emotion-laden information", their results were consistent with other researches' findings (Schutte et al., 2007; Joseph and Newman, 2010; Martins et al., 2010; Walter et al., 2011; O’Boyle et al., 2011; Miao et al., 2016, 2017a, 2017b, 2017c, 2018a, 2018b) indicated that emotionally intelligent individuals have the ability to control their emotions to remain positive and excited and to ease undesirable feelings in the place of work, thus resulting in positive outcomes like organizational commitment and organizational citizenship behaviors.

In spite of the evidence indicated by both Martins et al. (2010) and Resurrección et al. (2014) to link EI to better physical and mental health, Davis and Nichols (2016) suggested that high emotional alertness and managing may be related to bad psychological health and unfavorably effect on a person's capacity to deal with emotionally vital circumstances.

\section{4-2 Models of Emotional Intelligence (EI)}

\section{4-2-1 Ability Emotional Intelligence (AEI)}

Mayer et al. (2016) were the first researchers who labeled ability EI (AEI) as a set of abilities starting with perceiving emotions and ending with managing it. Wong and Law (2002) proposed four EI domains in terms of ability-based model: self-emotional awareness, using emotion, regulating emotion, and assessing emotions of others. They introduced the Wong and Law Emotional Intelligence Scale (WLEIS) to measure EI of individuals which was used in this study. Travis and Lac (2006) criticized AEI model as for the lack of both face and predictive validity in the workplace.

4-2-2 Trait Emotional Intelligence (TEI)

Mayer and other researchers declared that EI is an ability construct while other researchers have linked EI to other constructs like personality. This model led the way to substitute EI concept as an inherent trait rather than acquired abilities developed through experience. Petrides and Furnham (2000) indicated that TEI referred to consistencies in behavior based on situation while AEI referred to individual's capability to recognize, express, and label emotions in self and others. Professor of Psychology and Psychometrics Konstantinos V. Petrides proposed a conceptual difference between the AEI and TEI and developed the later over years (Petrides and Furnham, 2000; Petrides et al., 2007).

4-2-3 Mixed Emotional Intelligence

Mixed EI model includes inherited trait and acquired ability to effectively understand, use, and manage emotions, where Bar-On reengineered EI in contemporary times. Bar-On (2006) conceptualized EI as an accumulation of emotional and social intelligence (based on Thorndike 1920's theory of SI), a combination of emotional and social capabilities, emotional expression skills and strategies, understanding and relating to others, and the ability to manage daily stresses (Bar-On et al., 2004). Hence, Bar-On (2006) related EI to intrapersonal 
awareness, interpersonal awareness, and emotion management to manage personal, social, and environmental changes effectively through problem solving and good decision-making.

4-2-4 Comparison between different Emotional Intelligence Models

Davis and Nichols (2016) stated that trait EI as emotions were relevant to self-perceptions and natures, such as: sympathy, self-control while ability EI is the cognitive skills dedicated for processing emotional information, such as: emotion perception, understanding, which were different in their basic empirical bases and measurement methods as Petrides et al. (2007) and Mayer et al. (2008a) indicated that this was consistent with what Martins et al. (2010) stated concerning the differences in the way both trait EI and ability EI were measured. Davis and Humphrey (2014) and Salguero et al. (2015) indicated that TEI and AEI work in alternatively one behind the other to emphasize these effects; where high emotional skill levels accompanied with low emotional selfefficacy, result in highly depressed individuals.

\section{4-3 Big Five Personality Traits (BFPT)}

The Big Five Personality Traits (BFPT) refer to the differences in individual's patterns of thinking, feeling, and behaving. Soto and John (in press 2017) labeled the Big Five personality traits as Extraversion, Agreeableness, Conscientiousness, Negative Emotionality, and Open-Mindedness. While Goldberg (1993); John et al. (2008); McCrae and Costa (2008) labeled them as Extraversion, Agreeableness, Conscientiousness, Neuroticism contrasted with Emotional Stability, and Openness to Experience, Intellect, or Imagination. According to Soto and John (in press 2017), the five domains of the BFPT had 15 facets; Extraversion, Agreeableness, Conscientiousness, Negative Emotionality, and Open-Mindedness. This labeling was consistent with McCrae and John (1992) argument, as they described BFPT in terms of the same five basic dimensions; extraversion, agreeableness, conscientiousness, neuroticism, and openness to experience.

\section{4-4 Performance of Higher Education Institutions}

Performance is an important concept to achieve organizational goals, it was sometimes seen as the same meaning of success as indicated by Olusola (2011), others view it as goal-directed activities as per Godlovitch (1993). While Bierbusse and Siesfeld (1997) concluded that others see it as achievement of a certain task measured by certain predetermined standards like accurateness, comprehensiveness, cost, and speed, and others relate it to effectiveness, efficiency, and productivity (Berry et al., 2006; Tukamuhabwa et al., 2011; Gleason et al., 2000; and Hilman and Abubakar, 2017).

Higher education institutions are facing the same pressure as all other kind of organizations with respect to market competition, and due to aggressive competition, higher education institutions are adopting the model of other businesses in other fields so that dealing with students as customers as indicated by Zwain et al. (2012) and Hilman and Abubakar (2017), and since different stakeholder demands are getting more complex, educational institutions must keep up its competitive advantage (Zwain et al., 2012). As per Hazelkorn (2015), higher education institutions used both peer review and accreditation as performance assessment, where (Hilman and Abubakar, 2017) indicated that the results of such assessment tools were difficult to understand by ordinary people which leads to breaking down trust between stakeholders. Higgins (1989); Johnes and Taylor (1990); Ball and Wilkinson (1994); Hilman and Abubakar (2017) indicated that scholars have different beliefs about performance measurement, where some thought that evaluating performance must reproduce students' academic achievement only; in the meantime, others thought that it was vital to measure both students' academic achievement and nonstudents academic achievement.

\section{4-5 Previous Investigated Relationships}

Prati and Karriker (2018) indicated that a manager's emotional intelligence (MEI) might expressively decrease the deleterious effect of blue mood on employees' emotional performance. Miao et al. (2017a, 2017b) stated that emotionally intelligent persons are capable of regulating their emotions in order to be positive and enthusiastic and to reduce undesirable feelings in the workplace, accordingly resulting in positive outcomes such as organizational commitment, and organizational citizenship behaviors, higher job satisfaction. Sinha and Jain (2004); Mayer et al. (2004), Anwar et al. (2017) concluded significant relationships between others' emotion appraisal, use of emotion, and regulation of emotion aspects of EI with organizational citizenship behavior (OCB), while the only dimension of self-emotional appraisal is not found to have statistically significant relationship with OCB. Also, they indicate that people, with higher positive levels of EI, show higher levels of OCB which consequently lead to increased organization performance.

They confirmed that the relationship between self-emotional awareness and OCB was not significant, in spite of the fact that they have positive relationship among them. Self-emotional awareness refers to an individual's 
capability to understand their own emotions and be able to express those emotions. Furthermore, Wong and Law (2002) claimed that an individual's increased self-emotional awareness of the possibly negative impact of their behavior had little influence on the actual behavior they subsequently displayed. Newton et al. (2016) discussed the relationship between EI and understanding work environment, where high EI employees might easily understand the environment that enables more optimistic and less bad emotional responses for more adaptive coping, however high EI maximizes the destructive effects of job stressors such as overload, management difference, underload, and vagueness, on outcomes where significant interactions are found between role underload and management disagreement.

The relationship between both ability and trait EI with the Big Five measures was analyzed by van der Linden et al. (2017), indicating that TEI has strong correlation and basically identical with BF measures and with the social effectiveness dimension of personality, as people high in TEI are expected to behave in a successful social manner, which will consequently produce higher scores on personality aspects like friendliness, dependability, and sociability. People high in TEI are characterized by being extrovert, agreeable, conscientious, confident, and emotionally stable (Petrides, 2009a). Nevertheless, those with high AEI have greater emotional knowledge, awareness, and regulatory capability (Davis and Nichols, 2016).

\section{4-6 Measures}

\section{4-6-1 Measures of Emotional Intelligence}

A lot of EI measures are developed such as Bar-On Emotional Quotient Inventory (EQ-i) (Bar-On, 1997a,b), Self-report Emotional Intelligence Test (SREIT) (Schutte et al., 1998), Trait Emotional Intelligence Questionnaire (TEIQue) (Petrides and Furnham, 2001), Mayer-Salovey-Caruso Emotional Intelligence Tests (MSCEIT) (Mayer et al., 2002a,b), Emotional and Social competence Inventory (ESCI) (Boyatzis and Goleman, 2007), and both The Situational Test of Emotional Management (STEM) and The Situational Test of Emotional Understanding (STEU) (MacCann and Roberts, 2008). Petrides and Furnham (2000) were the first to distinguish between AEI and TEI based on whether the measure is testing highest performance (AEI) or a self-report questionnaire (TEI) (Pérez et al., 2005). Accordingly, AEI measures are based to emotional theoretic understanding of an individual, while TEI measures are based to usual behaviors in emotion-relevant situations and self-rated abilities.

Ability-measures are different than trait measures as they need participants to resolve problems related to emotion that have correct or incorrect answers. Since they were quizzes of highest ability, they cannot predict normal behavior like trait-based measures (O'Connor et al., 2017). Trait-based measures are referred to as those using self-report items to measure EI. Individuals scoring high in different TEI measures have great levels of self-efficacy concerning behaviors related to emotion and are capable of dealing with and regulating their emotions and others' emotions (O’Connor et al., 2019).

Mixed EI measures are used to develop surveys and questionnaires which include a mixture of traits, social skills and capabilities which are similar to other personality measures (O'Connor et al., 2019). A mutual feature amongst these measures is the concentration on emotional capabilities so that they can be improved to boost people's proficient achievement (Goleman, 1995). Each measure varies in the quality of its psychometric properties and predictive validity, Wong and Law (2002) have discussed the fact of the lack of a psychometrically sound practically short EI measure that was why they developed Wong and Law Emotional Intelligence Scale (WLEIS) a valid and reliable measure, providing evidence regarding the effects of EI on affecting job outcomes.

In this study, the researcher is interested in emotional abilities and competencies where a good theoretical understanding of emotions is required, as the researcher investigated higher management abilities and competencies effects on organization performance, and as indicated by Mayer et al. (2008b), high EI managers were experienced decision makers, problem solvers and negotiators due to their excessive capabilities at distinguishing and understanding emotions. Wong et al. (2004) developed a forced choice EI scale (WEIS) adopting the Mayer et al. (2000) explanation of EI as a specific group of mental capabilities, they used a Likerttype EI measure.

\section{4-6-2 Measures of the Big Five Personality Traits}

The 44-item Big Five Inventory developed by Benet-Martinez and John (1998) was used to assess the Big Five personality dimensions, test-takers were asked how much they agree or disagree to the statements they were answering. Big Five Inventory-2 (BFI-2) was a measured developed by Soto and John (in press 2017) consisting of a 60-question questionnaire assessing the Big Five domains and 15 facets: Extraversion, Agreeableness, 
Conscientiousness, Negative Emotionality, and Open-Mindedness. Soto and John (2017) developed and validated a 30-item short form (the BFI-2-S) and a 15-item extra-short form (the BFI-2-XS) based on the BFI-2. These shortened forms save assessment time; in addition, they preserve most of the BFI-2 measure's reliability and validity, particularly at the domain level.

\section{4-7 Hypotheses}

Based on the above discussion, the researcher formulates the main hypothesis assuming that the Big five personality traits have a mediating effect on the relationship between emotional intelligence and organization performance.

\section{Methodology}

\section{5-1 Introduction}

The current study examines the relationship between top management EI and organization performance within higher education institutions by mediating the BFPT. Although the topics of EI and organization performance have been examined using different variables than what is used in this study, their relationship to one another mediated by the BFPT has been studied in the literature.

\section{5-2 Conceptual Framework}

Since the current study is interested in studying the relationship between EI and organization performance using the BFPT in higher education institutions, and as this type of relationship was not investigated previously, the current study has investigated this relationship as demonstrated in the hereunder framework.

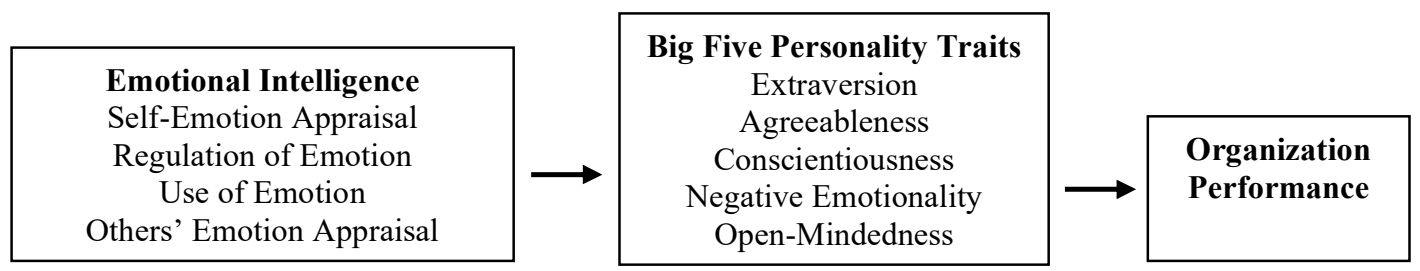

Fig. (1): Emotional Intelligence impact on Organization Performance Using the Big Five Personality Traits.

\section{5-3 Methodology and Design}

A quantitative correlation study is applied using Structural Equation Modeling (SEM) to examine the possible relationship between EI and organization performance using the BFPT in higher education institutions. A quantitative technique is appropriate as the purpose of the study is to measure the possible relationship between EI as an independent variable, and organization performance as a dependent variable, such correlation design is considered as a convenient way to examine the correlation between both dependent and independent variables.

\section{5-4 Survey Instrument and Sample}

The researcher uses a three-part self-administered questionnaire consisting of 50 questions. The survey used a 5point Likert-type scale, it consisted of 3 parts; the first one included 12 questions scale developed by Abubakar, Hilman and Kaliappen (2018) reflecting respondents' understanding of their current institution measuring organization performance; the second part reflected respondents' understanding of their dean's personality and traits including 31 questions about EI, and BFPT using Wong and Law Emotional Intelligence Scale (WLEIS), and Big Five Inventory-2-XS (BFI-2-XS) respectively, and the third part included 7 questions related to demographic aspects of respondents.

The population consisted of 1411 staff members. A stratified random sampling technique was used to ensure that participants in the sample represented the population. This probabilistic sampling method was chosen as the sample was targeting the different academic staff members representing four different occupational degrees within the institution, as well as classifying them according to specialties representing different specializations. Such probabilistic sampling method could accurately reflect population being studied. 


\section{Results and Analysis}

\section{6-1 Hypothesis Validity Test}

Validity test of the research hypothesis "There is a mediating effect of the Big five personality traits on the relationship between emotional intelligence and organizational performance", which was investigated using the Structural Equation Model (SEM).

\section{6-2 Description of the Model}

Variables of the model were classified according to their performance in the model, and coded as follows in order to be processed.

\begin{tabular}{|l|c|c|}
\hline \multicolumn{1}{|c|}{ Model Variables } & Variables Codes & Variables Type \\
\hline EI dimensions & & \\
1- Self-Emotion Appraisal & $\mathrm{X}_{1 \mathrm{t}}$ & Independent variable \\
2- Regulation of Emotion & $\mathrm{X}_{2 \mathrm{t}}$ & Independent variable \\
3-Use of Emotion Emotion & $\mathrm{X}_{3 \mathrm{t}}$ & Independent variable \\
4- Others $\quad \mathrm{X}_{4 \mathrm{t}}$ & Independent variable \\
Appraisal Ex dimensions & & \\
\hline BFPT & $\mathrm{Z}_{1 \mathrm{t}}$ & Mediating variable \\
1- Extraversion & $\mathrm{Z}_{2 \mathrm{t}}$ & Mediating variable \\
2- Agreeableness & $\mathrm{Z}_{3 \mathrm{t}}$ & Mediating variable \\
3- Conscientiousness & $\mathrm{Z}_{4 \mathrm{t}}$ & Mediating variable \\
4- Negative Emotionality & $\mathrm{Z}_{5 \mathrm{t}}$ & Mediating variable \\
5- Open-Mindedness & & \\
\hline Organization Performance & $\mathrm{Y}_{1 \mathrm{t}}$ & Dependent variable \\
10- Organization & & \\
Performance & & \\
\hline
\end{tabular}

Table (1): Classification of the structural model according to their nature and codes.

An estimated structural model was designed to examine the effect of emotional intelligence on organization performance mediated by the Big Five personality traits dimensions. As a result, it revealed that the estimated model emphasized that all of the independent variables of EI affected the three effective dimensions of the BFPT (extraversion, agreeableness, and open-mindedness), where the three effective dimensions chosen after trial and error trials to exclude non-effective ones. It was found that three BFPT effective dimensions affected the organization performance directly. Thus, it can be argued that all of the independent variables of EI affected indirectly the organization performance mediated by three of the BFPT (extraversion, agreeableness, and openmindedness).

But after studying the different paths' significance of the estimated model including CR test and covariance analysis, it was found that there was no significance for the presence of the independent variable self-emotion appraisal due to the lack of significance of its relationship with the three mediating variables; extraversion, agreeableness, and open-mindedness, Thus, there was no clear path linking self-emotion appraisal with the dependent variable organization performance within the model. Therefore, self-emotion appraisal should be removed from the model and another model should be re-estimated; the results of the adjusted model is displayed below.

\section{6-3 Adjusted Estimated Model}

The adjusted estimated model is presented by the figure below. The three effective BFPT dimensions were used to mediate the relationship, in addition "self-emotion appraisal" dimension of EI was omitted. 


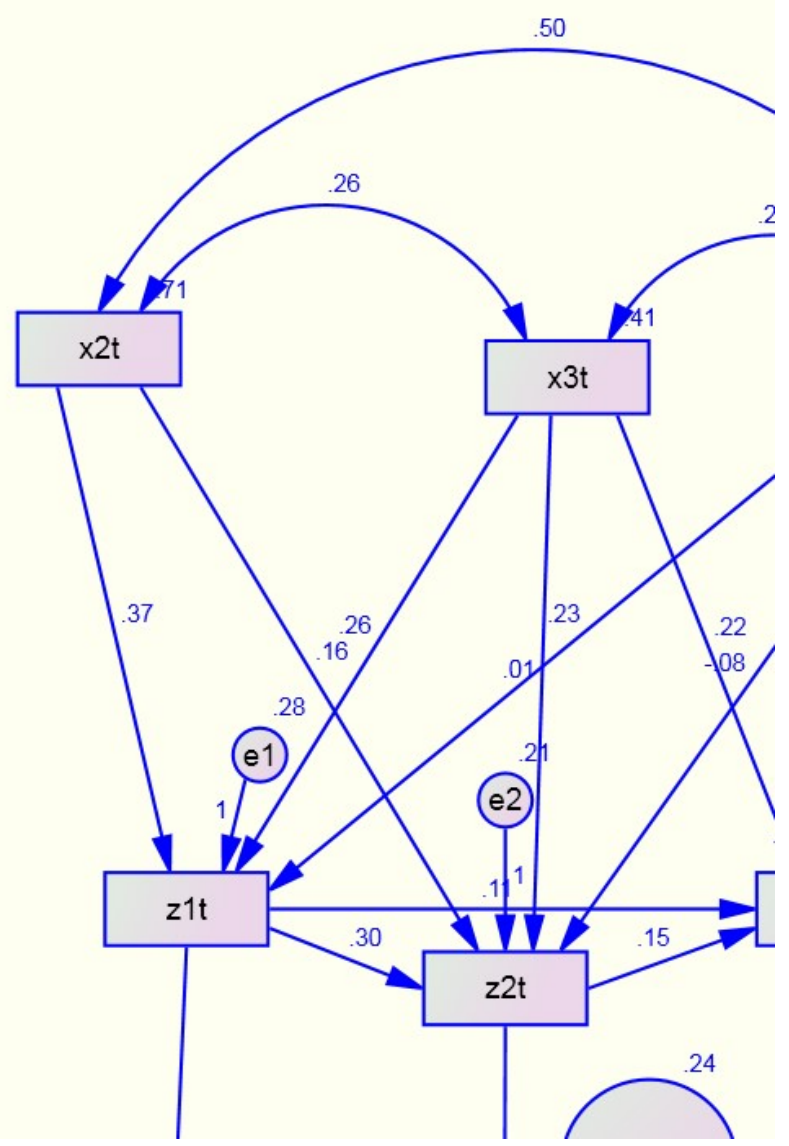

Figure (2) Adjusted estimated model displays the effect of three EI dimensions on organization performance by mediating extraversion, agreeableness, and open-mindedness as the effective BFPT variables.

The results confirmed that the three tested dimensions of EI as independent variables affected the three effective dimensions of the BFPT (extraversion, agreeableness, and open-mindedness) in the model, particularly after omitting the "self-emotion appraisal" EI dimension. The following demonstration shows the adjusted estimated model results.

\section{6-4 Adjusted Estimated Model Testing}

Adjusted structural model results after omitting the "self-emotion appraisal" EI dimension from the model.

\begin{tabular}{|l|c|c|c|c|}
\hline \multirow{2}{*}{ Test } & \multicolumn{3}{|c|}{ Tests Results } & \multirow{2}{*}{ Achievement } \\
\cline { 2 - 4 } & Test Value & df & Significance & \\
\hline Chi-Square & 12.762 & 4 & 0.012 ( Sig. at 0.05) & Not achieved \\
\hline $\begin{array}{l}\text { Standard Chi-Square (CMIN } \div \\
\text { df) }\end{array}$ & 2.460 & & & $<5$ Achieved \\
\hline
\end{tabular}

Table (2): Tests results of the adjusted model of emotional intelligence dimensions' effect on organization performance by mediating the BFPT.

Table (2) results have confirmed standard chi-square test achievement, as the value of the (CMIN $\div \mathrm{df}$ ) reached the optimal value (less than 5), reflecting achieving actual observation by the model to the predicted ones, even though chi-square test was significant. 


\section{6-5 Goodness-of-Fit Indicators of Adjusted Model}

The results of goodness-of-fit indicators of the adjusted model are presented below.

\begin{tabular}{|l|c|c|c|}
\hline \multicolumn{1}{|c|}{ Indicators } & $\begin{array}{c}\text { Indicators } \\
\text { Calculated Values }\end{array}$ & $\begin{array}{c}\text { Optimal } \\
\text { Value }\end{array}$ & $\begin{array}{c}\text { Optimal Value } \\
\text { Achievement }\end{array}$ \\
\hline Goodness-of-Fit Index (GFI) & 0.987 & $0.90+$ & Achieved \\
\hline Comparative Fit Index (CFI) & 0.987 & $0.90+$ & Achieved \\
\hline Root Mean Square Error (RMSE) & 0.090 & $0.05-0.08$ & Achieved \\
\hline
\end{tabular}

Table (3): Results of goodness-of-fit indicators of the adjusted model, indicating the quality of the model.

The results presented in table (3) emphasize that the values of both Goodness-of-Fit Index and Comparative Fit Index values were 0.987 and compared to the optimal value of $0.90+$, it is clear that the both indices values significantly and positively exceeded the optimal value. As for the Root Mean Square Error index, though the indicator's value was close to the optimal ones, the researcher could not be certain that the values calculated did not achieve the optimal value.

6-6 Different Paths' Significance Study of the Adjusted Model

The following table presents the estimated parameters significance results for all paths after adjustments.

\begin{tabular}{|c|c|c|c|c|c|}
\hline Serial & Paths & $\begin{array}{c}\text { Estimated } \\
\text { Parameters }\end{array}$ & $\begin{array}{l}\text { CR test } \\
\text { Values }\end{array}$ & $\begin{array}{c}\text { Significant } \\
\text { Value }\end{array}$ & Comment \\
\hline 1 & $\mathrm{X}_{2 \mathrm{t}} \longrightarrow \mathrm{Z}_{1 \mathrm{t}}$ & 0.374 & 7.014 & 0.000 & $\mathrm{P}<0.01$ \\
\hline 2 & $\mathrm{X}_{3 \mathrm{t}} \longrightarrow \mathrm{Z}_{1 \mathrm{t}}$ & 0.259 & 4.456 & 0.000 & $\mathrm{P}<0.01$ \\
\hline 3 & $\mathrm{X}_{4 \mathrm{t}} \longrightarrow \mathrm{Z}_{1 \mathrm{t}}$ & 0.235 & 4.830 & 0.000 & $\mathrm{P}<0.01$ \\
\hline 4 & $\mathrm{X}_{2 \mathrm{t}} \longrightarrow \mathrm{Z}_{2 \mathrm{t}}$ & 0.164 & 3.306 & 0.000 & $\mathrm{P}<0.01$ \\
\hline 5 & $\mathrm{X}_{3 \mathrm{t}} \longrightarrow \mathrm{Z}_{2 \mathrm{t}}$ & 0.009 & 0.168 & 0.867 & N.S \\
\hline 6 & $\mathrm{X}_{4 \mathrm{t}} \longrightarrow \mathrm{Z}_{2 \mathrm{t}}$ & -0.008 & -1.850 & 0.064 & N.S \\
\hline 7 & $\mathrm{Z}_{1 \mathrm{t}} \longrightarrow \mathrm{Z}_{2 \mathrm{t}}$ & 0.299 & 5.734 & 0.000 & $\mathrm{P}<0.01$ \\
\hline 8 & $\mathrm{X}_{3 \mathrm{t}} \longrightarrow \mathrm{Z}_{5 \mathrm{t}}$ & 0.218 & 4.214 & 0.000 & $\mathrm{P}<0.01$ \\
\hline 9 & $\mathrm{X}_{4 \mathrm{t}} \longrightarrow \mathrm{Z}_{5 \mathrm{t}}$ & 0.019 & 0.463 & 0.644 & N.S \\
\hline 10 & $\mathrm{Z}_{2 \mathrm{t}} \longrightarrow \mathrm{Z}_{5 \mathrm{t}}$ & 0.151 & 2.491 & 0.013 & $\mathrm{P}<0.05$ \\
\hline 11 & $\mathrm{Z}_{1 \mathrm{t}} \longrightarrow \mathrm{Z}_{5 \mathrm{t}}$ & 0.114 & 2.136 & 0.033 & $\mathrm{P}<0.05$ \\
\hline 12 & $\mathrm{Z}_{1 \mathrm{t}} \longrightarrow \mathrm{Y}_{1 \mathrm{t}}$ & 0.200 & 4.299 & 0.000 & $\mathrm{P}<0.01$ \\
\hline 13 & $\mathrm{Z}_{5 \mathrm{t}} \longrightarrow \mathrm{Y}_{1 \mathrm{t}}$ & 0.211 & 3.378 & 0.000 & $\mathrm{P}<0.01$ \\
\hline 14 & $\mathrm{Z}_{2 \mathrm{t}} \longrightarrow \mathrm{Y}_{1 \mathrm{t}}$ & 0.189 & 2.901 & 0.004 & $\mathrm{P}<0.01$ \\
\hline \multicolumn{6}{|c|}{ Covariance Analysis Results } \\
\hline 15 & $\mathrm{X}_{4 \mathrm{t}} \longleftrightarrow \mathrm{X}_{2 \mathrm{t}}$ & 0.501 & 9.040 & 0.000 & $\mathrm{P}<0.01$ \\
\hline 16 & $\mathrm{X}_{4 \mathrm{t}} \longleftrightarrow \mathrm{X}_{3 \mathrm{t}}$ & 0.241 & 6.320 & 0.000 & $\mathrm{P}<0.01$ \\
\hline 17 & $\mathrm{X}_{3 \mathrm{t}} \longleftrightarrow \mathrm{X}_{2 \mathrm{t}}$ & 0.257 & 7.038 & 0.000 & $\mathrm{P}<0.01$ \\
\hline
\end{tabular}

Table (4): Adjusted model estimated paths' parameters results studying the impact of EI dimensions on the organization performance mediated by the BFPT effective dimensions (extraversion, agreeableness, and openmindedness).

The results presented in table (4) confirm all paths significance except for some specific ones, including the three paths between $\mathrm{X}_{3 \mathrm{t}} \rightarrow \mathrm{Z}_{2 \mathrm{t}}, \mathrm{X}_{4 \mathrm{t}} \rightarrow \mathrm{Z}_{2 \mathrm{t}}$, and $\mathrm{X}_{4 \mathrm{t}} \rightarrow \mathrm{Z}_{5 \mathrm{t}}$. As for the covariance analysis results, they confirm the significance of the three relationships within EI domain; $X_{4 t} \longleftrightarrow X_{2 t}, X_{4 t} \longleftrightarrow X_{3 t}$, and $\mathrm{X}_{3 \mathrm{t}} \longleftrightarrow \mathrm{X}_{2 \mathrm{t}}$ at the level of significance 0.01 . 


\section{6-7 Adjusted Model Results of Direct and Indirect Effects}

The following table presents the adjusted model results of the direct and indirect effects.

\begin{tabular}{|c|c|c|c|c|c|c|c|c|c|c|c|c|}
\hline \multirow[t]{2}{*}{ Model Variables } & \multicolumn{4}{|c|}{ Direct Effect } & \multicolumn{4}{|c|}{ Indirect Effect } & \multicolumn{4}{|c|}{ Total Effect } \\
\hline & Z1t & Z2t & $\mathbf{Z 5 t}$ & Y1t & Z1t & Z2t & Z5t & Y1t & Z1t & Z2t & $\mathbf{Z 5 t}$ & Y1t \\
\hline $\begin{array}{c}\mathbf{X}_{4 \mathrm{t}} \\
\text { Others' Emotion } \\
\text { Appraisal }\end{array}$ & 0.235 & -0.080 & 0.019 & 0.000 & 0.000 & 0.070 & 0.025 & 0.054 & 0.235 & -0.010 & 0.044 & 0.054 \\
\hline $\begin{array}{c}\mathbf{X}_{3 \mathrm{t}} \\
\text { Use of Emotion }\end{array}$ & 0.259 & 0.009 & 0.218 & 0.000 & 0.000 & 0.077 & 0.043 & 0.123 & 0.259 & 0.086 & 0.260 & 0.123 \\
\hline $\begin{array}{c}\mathbf{X}_{2 \mathrm{t}} \\
\text { Regulation of } \\
\text { Emotion }\end{array}$ & 0.374 & 0.164 & 0.000 & 0.000 & 0.000 & 0.112 & 0.085 & 0.145 & 0.374 & 0.276 & 0.085 & 0.145 \\
\hline $\begin{array}{c}\mathbf{Z}_{1 \mathrm{t}} \\
\text { Extraversion }\end{array}$ & 0.000 & 0.299 & 0.114 & 0.200 & 0.000 & 0.000 & 0.045 & 0.090 & 0.000 & 0.299 & 0.159 & 0.289 \\
\hline $\begin{array}{c}\mathbf{Z}_{2 \mathrm{t}} \\
\text { Agreeableness }\end{array}$ & 0.000 & 0.000 & 0.151 & 0.189 & 0.000 & 0.000 & 0.000 & 0.032 & 0.000 & 0.000 & 0.151 & 0.221 \\
\hline $\begin{array}{c}\mathbf{Z}_{5 \mathrm{t}} \\
\text { Open-Mindedness }\end{array}$ & 0.000 & 0.000 & 0.000 & 0.211 & 0.000 & 0.000 & 0.000 & 0.000 & 0.000 & 0.000 & 0.000 & 0.211 \\
\hline
\end{tabular}

Table (5): Direct and indirect effects results within the adjusted model presenting the EI dimensions impact on organization performance mediated by the BFPT effective dimensions (extraversion, agreeableness, and openmindedness).

The results presented in table (5) confirm the fact that there are both direct and indirect effects of the variables listed in the table. Yet, the indirect effect is evident in the results of the independent variable, depending on the relationship nature, the three independent variables effect, and the extent to which they affect the dependent variable. However, the direct effect is mostly clear through the mediating variables. Therefore, the researcher can absolutely accept the validity of the hypothesis.

\section{Discussion and Conclusion}

The relationship between ability and trait emotional intelligence with the Big Five personality traits was previously studied. High TEI individuals were regarded as being extrovert, agreeable, conscientious, confident, and emotionally stable (Petrides, 2009a). While, those high in AEI had better emotional knowledge, awareness, and regulatory capability (Davis and Nichols, 2016).

In the present study, the relationship between emotional intelligence and organization performance through the Big Five personality traits within higher education institutions is examined. Since this relationship needs a proof to show EI contribution to organization performance, the respondents are assessing their college deans, as how they perceive their deans in their current roles.

Analysis of data includes Structural Equation Modeling, ANOVA, cluster analysis, one-way and correlational statistics to examine the relationships of the independent variables to the dependent variables. To test reliability and validity of all research dimensions and variables, Simple Pearson Correlation Coefficient and Cronbach's Alpha Coefficient are used. Chi-Square and Standard Chi-Square tests are used to examine the estimated models. Moreover, Goodness-of-Fit Index, Comparative Fit Index, and Root Mean Square Error are used to test estimated models' fit. Finally, CR test and covariance analysis are applied to study the different paths' significance of the estimated parameters within the estimated model. The goodness-of-fit of the re-estimated model has been proved.

Results have proved that EI has an indirect effect on organization performance, where no direct effect is shown when mediated the BFPT in the relationship. When investigating the significance of paths between variables, it is found that all are significant except for the three paths between $X_{3 t}$ and $Z_{2 t}, X_{4 t}$ and $Z_{2 t}$, and $X_{4 t}$ and $Z_{5 t}$. Results also have confirmed the significance of the three relationships between $X_{4 t}$ and $X_{2 t}, X_{4 t}$ and $X_{3 t}$, and $X_{3 t}$ and $X_{2 t}$.

It is found that not all the five traits of the BFPT mediated the relationship, also, not all emotional intelligence dimensions have played role in this relationship. Only agreeableness, conscientiousness, and open-mindedness of the BFPT are effective in the relationship between emotional intelligence and organizational performance. Also, self-emotion appraisal dimension of the EI lack the significance of its relationship with the three mediating variables; extraversion, agreeableness, and open-mindedness. Consequently, self-emotion appraisal is removed from the first model, as there is no clear path linking it with the dependent variable organization performance, and another model is re-estimated. Finally, results findings have supported the hypothesis assuming that the Big 
five personality traits have meditated the relationship between emotional intelligence and organizational performance.

This result is consistent to Sinha and Jain (2004); Mayer et al. (2004), Anwar et al. (2017) who concluded the significant relationships between others' emotion appraisal, use of emotion, and regulation of emotion dimensions of EI with organizational citizenship behavior, while the self-emotional appraisal dimension did not have a statistically significant relationship with OCB. Also, they indicated that employees with high EI, could effectively manage their emotional experiences leading to higher levels of OCB, thus leading to increased individual and organization performance. Also, Wong and Law (2002) argued that an individual's increased selfemotional awareness might possibly have a negative effect on their conduct. These results are similar to the results of the current study, which proves also the effectiveness of all of the EI dimensions except the selfemotion appraisal dimension in the relationship between EI and organization performance.

Also, results have confirmed the significance of the three relationships between different EI dimensions as follows: others' emotion appraisal and regulation of emotion, others' emotion appraisal and use of emotion, and use of emotion and regulation of emotion. When testing the paths significance between EI dimensions and the BFPT dimensions, it is found that all were significant except for the three paths between use of emotion and agreeableness, others' emotion appraisal and agreeableness, others' emotion appraisal and open-mindedness. These results are consistent with what Petrides, 2009a had concluded, indicating that individuals high in TEI is characterized by being extrovert, agreeable, conscientiousness, confident, and emotionally stable. While, those high in AEI have greater emotional knowledge, awareness, and regulatory capability, and both EI types included abilities that seem beneficial for effective social interactions (Davis and Nichols, 2016).

\section{Theoretical and Practical Implications}

From the results of the current empirical study, it provides some assessment and establishes knowledge about the top management's emotional intelligence effects and how it is related to their organization performance by mediating the big five personality traits. The study empirical evidences can contribute to advancing the existing knowledge in the fields of both emotional intelligence and organization performance in higher education institutions by showing the different effects of EI dimensions on organization performance.

It would be important for human resource experts to improve methods for increasing the levels EI and BFPT dimensions when they are lacked, thus enhancing organization performance. These study findings could generate awareness about the impact of conducting more researches on EI, BFPT, and organization performance by incorporating other constructs of interests. Additional studies could be established to find proper HR policies and strategies that might be provided to develop top management emotional capabilities as well as personality traits. It is also anticipated that these research findings might generate awareness and interests among HR experts in terms of recruitment and selection of employees with such desired capabilities and traits. HR professionals should help organization management to conduct required programs for training and development, and use psychological procedures to increase the EI level of employees as well as their personal traits in order to achieving high organization performance.

In summary, academic top management have high EI specifically the three dimensions; others' emotion appraisal, use of emotion, and regulation of emotion, and at the same time characterized by being agreeable, conscientious, and open-minded, help their organizations to achieve high performance in achieving high organization performance. The positive correlation between overall EI and organization performance through using the BFPT is perceived as an essential capability for effective top management within education sector. In order to manage effectively, high EI is required to improve top management self-awareness, to manage their own emotions and those of others, and improve their personality traits in order to manage according to their organizations expectations.

\section{Limitations and Future Research}

The current study uses self-reported survey which has the variance limitations of this common method. The Abubakar, Hilman and Kaliappen (2018), WLEIS, and BFI-2-XS scales are self-reported which are subject to issue of over or under estimations that cannot be controlled, hence further study should overlook this biasness by conducting other measures to compare results. Further empirical research could make significant contributions to the other business sectors as well as providing a comparative study between different demographic attributes such as gender and different age range. Scholars can develop researches to recognize the nature of effects EI and 
BFPT might have on employee's performance which can lift the goal of the organization and therefore achieve high performance. For this reason, EI and personality traits of both managers and employees should be measured, and according to that findings, suitable human resource interferences could be planned and executed for improving performance of both employees and organizations. Moreover, future researchers can also study the mediation effects of BFPT in the relationship between EI and organization performance in investigating the reason behind having some ineffective dimensions within the EI and BFPT domains when they are linked together in the current study. Employee personal beliefs and consequently organizations might differ from the national cultural perspective. So, further studies might fill the research gaps regarding these aspects. Expectantly, this paper could encourage more scholars to conduct more researchers in the field of emotional related studies that might contribute to the new scopes of organizational performance. In this regard, this research could be a start for conducting more studies in related fields for advancing the knowledge.

\section{References}

Anwar and Sulaiman, 2013. Exploratory study of emotional intelligence of international students in Malaysia: a phenomenological approach. In: 3rd International Conference on Management. pp.680-690.

Anwar, M., Osman-Gani, A., Fontaine, R. and Rahman, M., 2017. Assessing organizational citizenship behaviour through constructing emotional intelligence. Asia-Pacific Journal of Business Administration, 9(2), pp.105-117.

Ball, R. and Wilkinson, R., 1994. The use and abuse of performance indicators in UK higher education. Higher Education, 27(4), pp.417-427.

Bar-On, R., 1997a. Bar-On Emotional Quotient Inventory: User's Manual. Toronto, ON: Multihealth Systems.

Bar-On, R., 1997b. The Emotional Quotient Inventory (EQ-i): Technical manual. Toronto, ON: Multi-Health Systems, Inc.

Bar-On, R., 2006. The Bar-On model of emotional-social intelligence (ESI). Psicothema, 18, pp.13-25.

Bar-On, R., Tranel, D., Denburg, N., L. and Bechara, A., 2004. Exploring the neurological substrate of emotional and social intelligence. In: J. T. Cacioppo and G. G. Berntson, ed., Social neuroscience: Key readings. New York, NY: Psychology Press, pp.223-301.

Benet-Martínez, V. and John, O., 1998. Los Cinco Grandes across cultures and ethnic groups: Multitraitmultimethod analyses of the Big Five in Spanish and English. Journal of Personality and Social Psychology, 75(3), pp.729-750.

Berry, A., Sweeting, R. and Goto, J., 2006. The effect of business advisers on the performance of SMEs. Journal of Small Business and Enterprise Development, 13(1), pp.33-47.

Bierbusse, P. and Siesfeld, T., 1997. Measures that matter. Journal of Strategic Performance Measurement, 1(2), pp.6-11.

Boyatzis, R., E. and Goleman, D., 2007. Emotional and Social Competency Inventory. Boston, MA: The Hay Group.

Crawford, M., 2009. Getting to the heart of leadership: Emotion and Educational Leadership. London, England: SAGE.

Davis, S. and Humphrey, N., 2014. Ability versus Trait Emotional Intelligence. Journal of Individual Differences, 35(1), pp.54-62.

Davis, S. and Nichols, R., 2016. Does Emotional Intelligence have a "Dark" Side? A Review of the Literature. Frontiers in Psychology, 7(Article 1316).

Gleason, K., Mathur, L. and Mathur, I., 2000. The Interrelationship between Culture, Capital Structure, and Performance: Evidence from European retailers. Journal of Business Research, 50(2), pp.185-191.

Godlovitch, S., 1993. The Integrity of Musical Performance. The Journal of Aesthetics and Art Criticism, 51(4), pp.573-587. 
Goldberg, L., 1993. The structure of phenotypic personality traits. American Psychologist, 48(1), pp.26-34.

Goleman, D., 1995. Emotional intelligence. New York: Bantam Books.

Hazelkorn, E., 2015. Rankings and the reshaping of higher education: The battle for world-class excellence. Basingstoke, UK: Palgrave Macmillan.

Higgins, J., 1989. Performance measurement in universities. European Journal of Operational Research, 38(3), pp.358-368.

Hilman, H. and Abubakar, A., 2017. Strategic talent management and university performance: A theoretical perspective. European Journal of Business and Management, 9(4), pp.35-40.

John, O., P., Naumann, L., P. and Soto, C., J., 2008. Paradigm shift to the integrative Big-Five trait taxonomy: History, measurement, and conceptual issues. In: O. P. John, R. W. Robins and L. A. Pervin, ed., Handbook of personality: Theory and research, 3rd ed. New York, NY: Guilford, pp.114-158.

Johnes, J. and Taylor, J., 1990. Performance indicators in higher education. Buckingham. Buckingham, UK: Society for Research into Higher Education \& Open University Press.

Joseph, D. and Newman, D., 2010. Emotional intelligence: An integrative meta-analysis and cascading model. Journal of Applied Psychology, 95(1), pp.54-78.

MacCann, C. and Roberts, R., 2008. New paradigms for assessing emotional intelligence: Theory and data. Emotion, 8(4), pp.540-551.

Martins, A., Ramalho, N. and Morin, E., 2010. A comprehensive meta-analysis of the relationship between Emotional Intelligence and health. Personality and Individual Differences, 49(6), pp.554-564.

Mayer, J., Caruso, D. and Salovey, P., 2016. The Ability Model of Emotional Intelligence: Principles and Updates. Emotion Review, 8(4), pp.290-300.

Mayer, J. and Salovey, P., 1997. What is emotional intelligence?. In: P. Salovey and D. J. Sluyter, ed., Emotional development and emotional intelligence: Educational implications. pp.3-34.

Mayer, J., Salovey, P. and Caruso, D., 2002a. Mayer-Salovey-Caruso Emotional Intelligence Test (MSCEIT) Booklet. Toronto, ON: MHS Publishers.

Mayer, J., Salovey, P. and Caruso, D., 2002b. Mayer-Salovey-Caruso Emotional Intelligence Test (MSCEIT) User's Manual. Toronto, ON: MHS Publishers.

Mayer, J., Salovey, P. and Caruso, D., 2004. Emotional intelligence: theory, findings, and implications. Psychological Inquiry, 15(3), pp.197-215.

Mayer, J., Salovey, P. and Caruso, D., 2000. Models of emotional intelligence. In: R. Sternberg, ed., Handbook of intelligence. New York, NY: Cambridge University Press, pp.396-420.

Mayer, J., Roberts, R. and Barsade, S., 2008a. Human Abilities: Emotional Intelligence. Annual Review of Psychology, 59(1), pp.507-536.

Mayer, J., Salovey, P. and Caruso, D., 2008b. Emotional intelligence: New ability or eclectic traits?. American Psychologist, 63(6), pp.503-517.

McCrae, R. and John, O., 1992. An Introduction to the Five-Factor Model and Its Applications. Journal of Personality, 60(2), pp.175-215.

McCrae, R., R. and Costa, P., T., 2008. The Five-Factor theory of personality. In: O. P. John, R. W. Robins and L. A. Pervin, ed., Handbook of personality: Theory and research, 3rd ed. New York, NY: Guilford, pp.159-181.

Miao, C., Humphrey, R. and Qian, S., 2017a. A meta-analysis of emotional intelligence and work attitudes. Journal of Occupational and Organizational Psychology, 90(2), pp.177-202. 
Miao, C., Humphrey, R. and Qian, S., 2016. Leader emotional intelligence and subordinate job satisfaction: A meta-analysis of main, mediator, and moderator effects. Personality and Individual Differences, 102, pp.13-24.

Miao, C., Humphrey, R. and Qian, S., 2017c. A meta-analysis of emotional intelligence effects on job satisfaction mediated by job resources, and a test of moderators. Personality and Individual Differences, 116 , pp.281-288.

Miao, C., Humphrey, R. and Qian, S., 2017b. Are the emotionally intelligent good citizens or counterproductive? A meta-analysis of emotional intelligence and its relationships with organizational citizenship behavior and counterproductive work behavior. Personality and Individual Differences, 116, pp.144-156.

Miao, C., Humphrey, R. and Qian, S., 2018a. A cross-cultural meta-analysis of how leader emotional intelligence influences subordinate task performance and organizational citizenship behavior. Journal of World Business, 53(4), pp.463-474.

Miao, C., Humphrey, R. and Qian, S., 2018b. Emotional intelligence and authentic leadership: a metaanalysis. Leadership \& Organization Development Journal, 39(5), pp.679-690.

Newton, C., Teo, S., Pick, D., Ho, M. and Thomas, D., 2016. Emotional intelligence as a buffer of occupational stress. Personnel Review, 45(5), pp.1010-1028.

O’Connor, P., Hill, A., Kaya, M. and Martin, B., 2019. The Measurement of Emotional Intelligence: A Critical Review of the Literature and Recommendations for Researchers and Practitioners. Frontiers in Psychology, 10 .

O’Boyle, E., Humphrey, R., Pollack, J., Hawver, T. and Story, P., 2011. The relation between emotional intelligence and job performance: A meta-analysis. Journal of Organizational Behavior, 32(5), pp.788-818.

Olusola, O., A., 2011. Accounting skill as a performance factor for small businesses in Nigeria. Journal of Emerging Trends in Economics and Italic Management Sciences, 25, pp.732-738.

Pérez, J., C., Petrides, K., V. and Furnham, A., 2005. Measuring Trait Emotional Intelligence. In: R. Schulze and R. D. Roberts, ed., Emotional intelligence: An International Handbook. Cambridge, MA: Hogrefe \& Huber, pp.181-201.

Petrides, K. and Furnham, A., 2000. On the dimensional structure of emotional intelligence. Personality and Individual Differences, 29(2), pp.313-320.

Petrides, K. and Furnham, A., 2001. Trait emotional intelligence: psychometric investigation with reference to established trait taxonomies. European Journal of Personality, 15(6), pp.425-448.

Petrides, K., Pita, R. and Kokkinaki, F., 2007. The location of trait emotional intelligence in personality factor space. British Journal of Psychology, 98(2), pp.273-289.

Petrides, K., V., 2009a. Psychometric properties of the Trait Emotional Intelligence Questionnaire (TEIQue). In: C. Stough, D. H. Saklofske and J. D. A. Parker, ed., Assessing emotional intelligence: Theory, research, and applications. New York, NY: Springer Science, pp.85-101.

Prati, L. and Karriker, J., 2018. Acting and performing: influences of manager emotional intelligence. Journal of Management Development, 37(1), pp.101-110.

Resurrección, D., Salguero, J. and Ruiz-Aranda, D., 2014. Emotional intelligence and psychological maladjustment in adolescence: A systematic review. Journal of Adolescence, 37(4), pp.461-472.

Salguero, J., Extremera, N., Cabello, R. and Fernández-Berrocal, P., 2015. If You Have High Emotional Intelligence (EI), You Must Trust in Your Abilities. Journal of Psychoeducational Assessment, 33(1), pp.46-56.

Salovey, P. and Mayer, J., 1990. Emotional Intelligence. Imagination, Cognition and Personality, 9(3), pp.185211. 
Schutte, N., Malouff, J., Hall, L., Haggerty, D., Cooper, J., Golden, C. and Dornheim, L., 1998. Development and validation of a measure of emotional intelligence. Personality and Individual Differences, 25(2), pp.167-177.

Schutte, N., Malouff, J., Thorsteinsson, E., Bhullar, N. and Rooke, S., 2007. A meta-analytic investigation of the relationship between emotional intelligence and health. Personality and Individual Differences, 42(6), pp.921-933.

Soto, C. and John, O., 2017. Short and extra-short forms of the Big Five Inventory-2: The BFI-2-S and BFI-2XS. Journal of Research in Personality, 68, pp.69-81.

Soto, C. and John, O., in press 2017. The next Big Five Inventory (BFI-2): Developing and assessing a hierarchical model with 15 facets to enhance bandwidth, fidelity, and predictive power. Journal of Personality and Social Psychology, 113(1), pp.117-143.

Thorndike, R., K., 1920. Intelligence and its uses. Harper's Magazine, 140, pp.227-335.

Travis, R., B. and Lac, D., S., 2006. Ability-versus skill-based assessment of emotional intelligence. Psicothema, 18 , pp.59-66.

Tukamuhabwa, B., R., Eyaa, S. and Friday, D., 2011. Mediating variables in the relationship between market orientation and supply chain performance: A theoretical approach. International Journal of Business and Social Science, 2(22), pp.99-107.

van der Linden, D., Pekaar, K., Bakker, A., Schermer, J., Vernon, P., Dunkel, C. and Petrides, K., 2017. Overlap between the general factor of personality and emotional intelligence: A meta-analysis. Psychological Bulletin, 143(1), pp.36-52.

Walter, F., Cole, M. and Humphrey, R., 2011. Emotional Intelligence: Sine Qua Non of Leadership or Folderol?. Academy of Management Perspectives, 25(1), pp.45-59.

Wong, C. and Law, K., 2002. The effects of leader and follower emotional intelligence on performance and attitude. The Leadership Quarterly, 13(3), pp.243-274.

Wong, C., Law, K. and Wong, P., 2004. Development and Validation of a Forced Choice Emotional Intelligence Measure for Chinese Respondents in Hong Kong. Asia Pacific Journal of Management, 21(4), pp.535-559.

Zwain, A. A., A., Teong, L., K. and Othman, S., N., 2012. Knowledge management processes and academic performance in Iraqi HEIs: An empirical investigation. International Journal of Academic Research in Business and Social Sciences, 2, pp.273-293. 